\title{
Performance Evaluation of Gravel Road Sections Sealed Using Open Graded Premix Surfacing with Bitumen and Bitumen Emulsion as the Binders
}

\author{
Dasari Rohith $^{1} \cdot$ Kakara Srikanth $^{1} \cdot$ Venkaiah Chowdary $^{1}$ - C. S. R. K. Prasad ${ }^{1}$
}

Received: 29 September 2015/Accepted: 7 June 2016/Published online: 14 June 2016

(C) Springer International Publishing Switzerland 2016

\begin{abstract}
In developing countries like India, rural areas lack adequate transportation facilities. The Ministry of Rural Development (MoRD), Government of India (GoI) decided to develop rural roads under Pradhan Mantri Gram Sadak Yojana (PMGSY). The objective of this program is to achieve connectivity to all habitations under different climatic conditions. There are certain disadvantages associated with construction of the rural roads using gravel like dust generation, gravel loss over a period of time due to passage of vehicles and inaccessibility during rains. The best solution to reduce these problems is to seal the gravel roads instead of maintaining it, since many studies showed that the maintenance of unsealed road is more costly than the sealed road over a period of time. Hence, a project has been taken up to give full and all weather connectivity using locally available materials. Up to the surface course, the selected road was constructed using the locally available gravel. Many sealing techniques are available, out of which, open graded premix surfacing (OGPS) was opted in this study. This paper aims at studying the performance evaluation of gravel surface sealed with OGPS. The variables considered in this study are: gravel surface type, primer rate, and binder type. Past researchers found that the roughness, skid resistance and texture depth significantly affect the performance of sealed gravel roads and these three parameters are considered as performance indicators in this study. Eight sets of data were collected at regular intervals starting from November 2013 to March 2015. The
\end{abstract}

Venkaiah Chowdary

chowdaryazad@gmail.com

1 Transportation Division, Department of Civil Engineering, National Institute of Technology, Warangal, Telangana 506004, India surface distresses were also measured. From the analysis it was observed that the roughness on emulsion based OGPS was more when compared to bitumen based OGPS. Emulsion based OGPS resulted in less texture depth when compared to bitumen based OGPS. Skid resistance varied differently with respect to the binder type, type of surface course and priming rate. Even though there is little effect of gravel surface course type on roughness and texture depth, the effect of primer rate on roughness, texture depth, and skid resistance is negligible.

Keywords Bitumen - Bitumen emulsion - Gravel road · Open graded premix surfacing $\cdot$ Performance evaluation

\section{Introduction}

Rural road connectivity is an important component of rural development, since it promotes access to economic and social services and thereby generating increased employment, agricultural productivity, which in turn expand rural growth opportunities through which poverty can be reduced. The Ministry of Rural Development (MoRD), Government of India (GoI) has decided to develop various rural roads under Pradhan Mantri Gram Sadak Yojana (PMGSY) program starting from the year 2000-2001. The program (PMGSY) is adopted to provide all weather connectivity to all the habitations with population more than 500 (250 for hilly states, desert areas and tribal areas) by the end of tenth 5 year plan i.e. by 2007 [1]. However, after 15 years of implementation of the programme, only $63 \%$ of the habitations have been connected by PMGSY roads. Recently, the GoI has brought forward the target date for full completion of rural road connectivity under PMGSY by 3 years from 2022 to 2019 through enhancement in funds allocation 
[2]. The PMGSY program fulfils one of the objectives of the tenth 5 year plan which emphasizes connectivity to all in a time bound manner. PMGSY emphasizes on maximizing the utilization of locally available materials in an attempt to reduce the cost of construction. Gravel is a cheap material and can be used in subgrade, sub-base, base, and surface courses. Gravel roads are generally considered as low service providing roads and are important components of the road transportation network. In many developing countries, more than $75 \%$ of the road network consists of gravel and earth roads. Aggregate surfaced roads are referred to as unpaved roads [3, 4]. Gravel pavement will not only carry traffic loads but will also be resistant to shear deformation and wear i.e. they have sufficient strength and durability [5]. Further, the gravel roads can also withstand the stresses coming on to the lower layers of the pavement. In wet weather conditions, gravel roads might develop distresses such as rutting and potholes. In dry seasons, gravel roads become dusty and results in corrugations. Thus sealing of the gravel roads minimizes percolation of rain water into the pavements and also reduces dust pollution.

The performance evaluation of various sealing techniques was explored by several researchers in the past. It is important to identify various sealing options and also the distress parameters which need to be considered for performance evaluation of the sealed gravel roads. Thus, the literature review is divided into two components. The first part of literature review is aimed at the identification of distress parameters for various sealing options whereas in the second part, various sealing options are explored both as a preventive maintenance treatment and also for the sealing of gravel roads.

Thin bituminous surfacing less than $40 \mathrm{~mm}$ depth is not expected to contribute significantly to the structural capacity of the pavement as the stresses are dissipated through the depth of granular layers provided above the subgrade [6]. Thus cracking need not be considered as a structural failure for thin bituminous surfacing and permanent deformation which is usually seen on the surface as rutting may be considered as a major structural failure in case of granular pavements with thin bituminous surfacing $[7,8]$. Further, thin bitumen surfaced roads fail by breaking of the thin surfacing before the terminal condition is reached resulting in higher unevenness and it is recommended to consider roughness as a major parameter in performance evaluation [5]. Apart from rutting and roughness, other functional indicators such as skid resistance and texture depth can also be used for the evaluation of thin surfaced roads. Surface dressing or chip seal is considered as one of the popular maintenance alternative wherein skid resistance and surface texture changes with time due to embedment of aggregate particles into the bitumen layer $[9,10]$.
Works are also reported on usage of several sealing options to defer major preventive maintenance. Chip seals and sand seals were effectively used in the past for preventive maintenance. It is important to consider not only the performance jump immediately after the application of a sealing option, but also to consider the rate of deterioration over a long-run [11]. Within a particular sealing option, the type of binder also plays a significant role on the performance of the sealing option. Chip seals constructed using bitumen emulsion as the binder is cost effective and result in a performance that is comparable with bitumen as the binder. Bitumen emulsion chip seal performance is better than bitumen chip seal in terms of the skid resistance evaluated over long-run [12]. Condition of the underlying layer over which a sealing option is applied can significantly affect the performance of the selected sealing option [10]. Sealing options can also preserve the structural capacity of low volume pavements [13]. It is important to note here that all the above studies focussed on sealing options when the base course is made of a water bound macadam (aggregate base course) or when the sealing option is used to defer the need for major preventive maintenance for existing bituminous pavements (maintenance sealing option).

Few studies related to sealing of gravel roads are reported in the literature. Some of the significant works are reported here. Poor performance was reported for sealing options including Otta seal and Gravseal laid over gravel surfaces in South Africa. However, the performance was better where high quality aggregate were used [14]. Otta seal applied over gravel roads in Lithuania resulted in several distresses within 1 year of construction [15]. Otta seal uses graded aggregate and thicker layer of soft bitumen. Even though several sealing options are reported in the literature, the sealing option do not add any strength to the pavement and the performance of any sealing option very much depends on the characteristics of the underlying layer. Performance of chip seal, Otta seal, and oil gravel depended on the stability of the underlying layers [16]. Works are also reported in recent years citing the benefits of Otta seal surfacing compared to other alternatives [4]. Some works related to influence of binder type and primer rate are also reported in the literature. In some of the south east Asian countries such as Vietnam, Cambodia and Lao, gravel roads were widely used in earlier days. However, maintenance of the gravel roads proved to be expensive when compared to sealed surfaces. This resulted in development of appropriate sealing techniques for gravel roads in those countries. No significant difference between performance of hot bitumen and bitumen seals were observed [17]. Further, it is also reported that the application rates of primer depends on the type of material and permeability characteristics of the layer to be primed [18]. 
It is important to note that the performance of the sealing options very much depends on the type of materials available locally, quality of construction, type and volume of traffic and climatic conditions of the region. Some of the sealing options that are proven to be successful in some parts of the world failed in other countries. Thus, the focus of this study is to evaluate the performance of a seal option when gravel is used in the base course. Gravel roads are constructed when volume of commercial traffic (gross weight exceeding 3 tonnes) is less. However, Indian Roads Congress [19] recommends bituminous surfacing over gravel surface course under following circumstances:

- Where subgrade is very poor $(\mathrm{CBR}=2 \%)$ and design traffic is in the range of 30,000 to 60,000 equivalent standard axle loads (ESALs),

- Where subgrade is poor (CBR $<4 \%$ ) and design traffic is in the range of 60,000 to $1,00,000$ ESALs, and

- Irrespective of the subgrade strength, the design traffic is greater than 1,00,000 ESALs.

Due to the movement of traffic and climatic changes over a period of time, the issues with gravel are numerous like dust generation, gravel loss, safety hazard, health hazard, discomfort and nuisance, air pollution, and inaccessibility of roads during rainy season. This leads to increased maintenance cost in terms of regravelling. Maintenance of gravel roads is expensive, especially periodic regravelling. In order to eliminate these effects and to improve the performance of the gravel roads, the best alternate is to seal the gravel roads. Thus, the main objective of this study is to evaluate the performance of gravel surface sections sealed with Open Graded Premix Surfacing (OGPS). It is worth noting here that OGPS with seal coat has been the most widely used wearing course in the construction PMGSY roads especially when the base course is Water Bound Macadam layer. Even though some of the sealing options were tried in the past, there is no mention in the published literature on the use of OGPS as a sealing option. Further, the influence of binder type and priming rate are not clearly established in the literature. An attempt has been made in this research to evaluate the performance of OGPS sealed gravel road wherein the influence of binder type and primer rate are also explored.

\section{Experimental Program}

The surface treatments require a strong stable base to work properly and the sealed layer constructed on strong stable base will lower the distresses [16]. Since the performance of thin bituminous sealing option depends very much on the characteristics of the underlying layer [10],
Table 1 Properties of aggregate

\begin{tabular}{llll}
\hline S. no. & Property & $\begin{array}{l}\text { Test result } \\
(\%)\end{array}$ & $\begin{array}{l}\text { Specifications } \\
{[20]}\end{array}$ \\
\hline 1 & $\begin{array}{c}\text { Combined flakiness and } \\
\text { elongation index }\end{array}$ & 28 & Max. 30\% \\
2 & $\begin{array}{l}\text { Aggregate impact value } \\
3\end{array}$ & 17 & Max. 30\% \\
4 & $\begin{array}{l}\text { Water absorption } \\
\text { Retained coating of } \\
\text { bitumen over aggregates }\end{array}$ & 0.90 & Max. 1\% \\
& & & Min. 95 \% \\
\hline
\end{tabular}

the recommended CBR value for the gravel surface and gravel base course is fixed at $30 \%$ in accordance with the guidelines of Ministry of Rural Development in India [20]. However, the gravel samples obtained from the local quarries failed to meet the requirement. Thus, the gravel was modified by blending with suitable proportion of aggregate. The existing gravel sub-base has a CBR value of $7 \%$. The gravel sub-base soil was blended using locally available gravel and brought to the required CBR of $15 \%$ as recommended by MoRD specifications [20]. The physical properties of aggregates used in the construction of surface sealing are shown in Table 1. Slow setting cationic bitumen emulsion was used for priming. VG-10 (80/100 penetration grade) bitumen [B] and medium setting cationic bitumen emulsion [E] were used for the construction of surface sealing.

The longitudinal section of the road and the sub-sections along with the chainage are shown in Fig. 1. Two types of gravel surface courses are used. First type of surface course (surface course type-1 $\left[\mathrm{T}_{1}\right]$ ) consists of $50 \%$ of gravel, $40 \%$ of $12.5 \mathrm{~mm}$ passing chips and $10 \%$ of $4.75 \mathrm{~mm}$ passing aggregates where the gravel was collected from first quarry. Second type of surface type (surface course type-2 $\left[\mathrm{T}_{2}\right]$ ) consists of $60 \%$ of gravel, $20 \%$ of $12.5 \mathrm{~mm}$ passing aggregates and $20 \%$ of $4.75 \mathrm{~mm}$ passing aggregates where the gravel was collected from a second quarry. Both the gravel surface course types were designed with a target soaked CBR of $30 \%$. Two types of prime coats were used i.e. priming-1 $\left(\mathrm{P}_{1}\right)$ at the rate of $9 \mathrm{~kg}$ per $10 \mathrm{~m}^{2}$ and priming-2 $\left(\mathrm{P}_{2}\right)$ at the rate of $12 \mathrm{~kg}$ per $10 \mathrm{~m}^{2}$. OGPS was used for sealing the gravel road in this study. OGPS is a sealing technique with $20 \mathrm{~mm}$ thick layer composed of small sized aggregate premixed with bituminous binder followed by a layer of seal coat (to seal voids in the bituminous surface). The pavement section was designed according to the relevant Indian standards [19].

Two gravel sections sealed with bitumen based OGPS and two sections sealed with emulsion based OGPS from the chainage $3 / 630$ to $7 / 045$ are considered. This surface treatment is considered for regular performance evaluation. The thickness of OGPS is only $20 \mathrm{~mm}$ and has no 


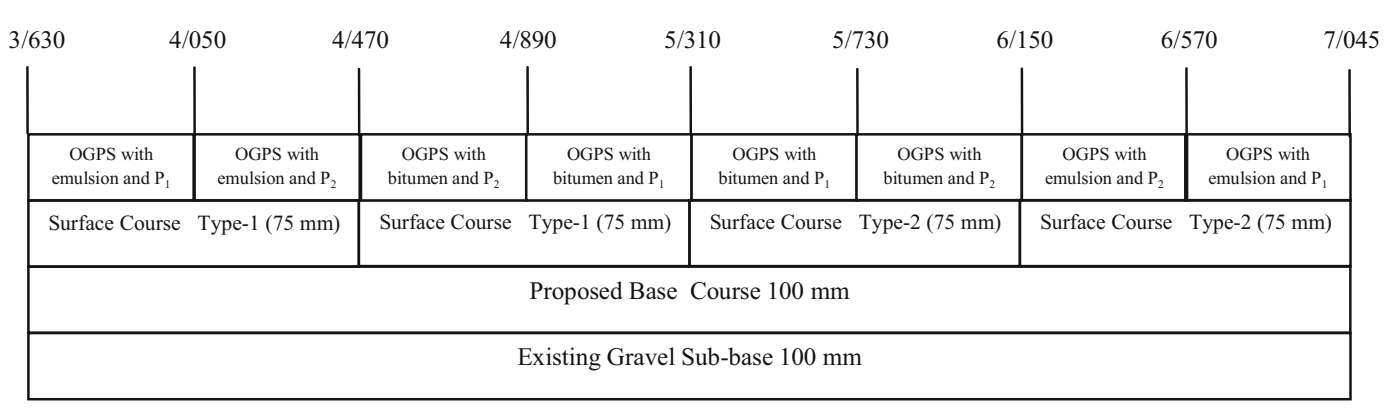

Fig. 1 Longitudinal section of the road showing various sub-sections

structural strength. However, the performance of OGPS can significantly affect the structural behaviour of the pavement. For instance, when the surface sealing is weak or with the onset of early surface cracking. The performance of each test section is evaluated by comparing skid resistance, texture depth and roughness. Roughness is the irregularities present in the pavement surface which affects the riding quality and was measured using Machine for Evaluating Roughness using Low cost Instrumentation (MERLIN). Skid resistance is a parameter that develops between a vehicle's tyres and the surface of the road and was measured by using British pendulum. Aggregate retention and resistance to bleeding was evaluated through the mean texture depth (MTD). Sand patch test was performed to measure the mean texture depth. Roughness, skid resistance and texture depth are the important parameters which have significant impact on the performance of gravel roads sealed with thin wearing courses.

\section{Evaluation of Parameters}

\section{Roughness}

Roughness is irregularity or deviation from a level surface. Road roughness affects the riding quality of a vehicle, vehicle operating cost, and maintenance cost. Roughness is indicated in terms of cumulative measure of vertical displacements as recorded by a recording wheel due to the unevenness in the longitudinal profile of the road and are measured in terms of $\mathrm{m} / \mathrm{km}$. MERLIN was used to evaluate the roughness over selected road stretches. The width of MERLIN histogram (D) was used to estimate road roughness on the International Roughness Index (IRI) scale using Eq. (1) [21].

IRI $=0.593+0.0471 \times \mathrm{D}$, when $2.4<$ IRI $<15.9$,

where, IRI is the roughness in terms of the International Roughness Index in $\mathrm{m} / \mathrm{km}$, and $\mathrm{D}$ is measured from the MERLIN chart in $\mathrm{mm}$.
In this study, the measurements were taken on both Left Hand Side (LHS) and Right Hand Side (RHS) of the pavement and the average value is considered for the calculation of IRI. Roughness measurements were taken after 7 months of construction of sealing layer i.e., in November 2013, January 2014, April 2014, June 2014, September 2014, November 2014, January 2015 and March 2015 for the selected road stretches. The average IRI values are shown in Figs. 2 and 3 where the maximum and minimum IRI values are represented using the range bars. In Fig. 2, emulsion based open graded premix surfacing with surface course type-1 (OGPSET1) is compared with bitumen based open graded premix surfacing with surface course type-1 (OGPSBT1). In Fig. 3, emulsion based open graded premix surfacing with surface course type-2 (OGPSET2) is compared with bitumen based open graded premix surfacing with surface course type-2 (OGPSBT2). There is no significant difference in the results shown in Figs. 2 and 3. The value of roughness increased with increase in time period due to the movement of traffic on the road. When bitumen is used as the binder, the roughness values are less when compared to emulsion. The difference is significant

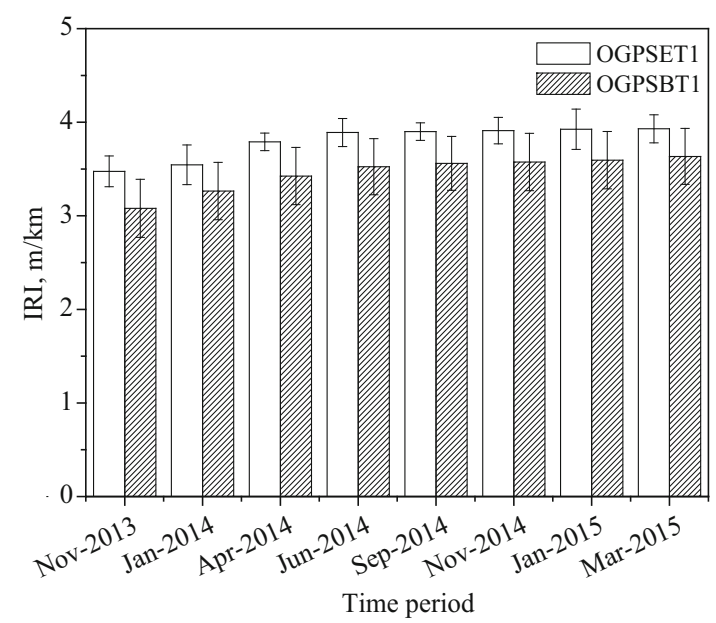

Fig. 2 IRI as a function of time for OGPS laid over gravel surface course type 1 


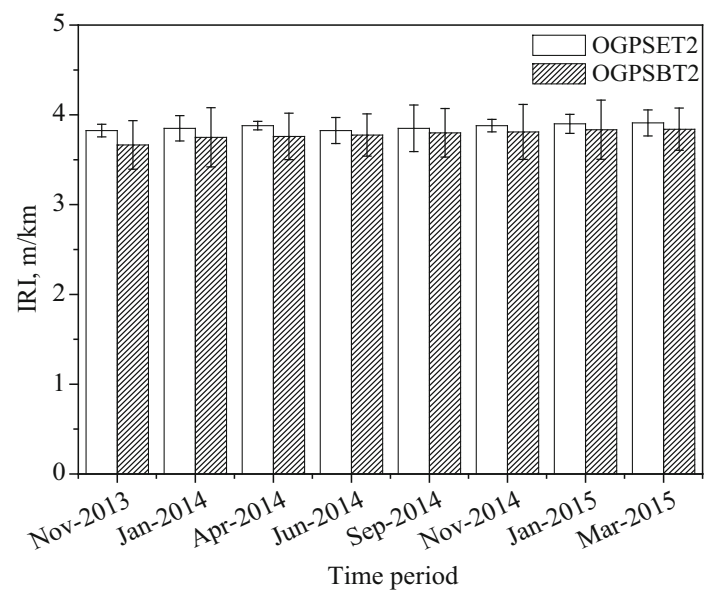

Fig. 3 IRI as a function of time for OGPS laid over gravel surface course type 2

in case of gravel surface course type 1 when compared to gravel surface course type 2 .

In Fig. 4, roughness on all the road sections is compared. There is an increase in roughness in all the road sections with increase in time. This is essentially due to accumulation vertical compressive strains over the test section due to movement of commercial vehicles. Lower roughness was recorded when bitumen is used as the binder. The parent bitumen present in the bitumen emulsion might be relatively softer than the bitumen binder resulting in higher roughness values when bitumen emulsion is used as the binder. The difference in IRI values between sections with bitumen and bitumen emulsion constructed over gravel surface course type 1 is higher than gravel surface course type 2. It is important to note here that both the surface course types are designed for $30 \% \mathrm{CBR}$. If the data is carefully observed, the initial (November 2013) IRI

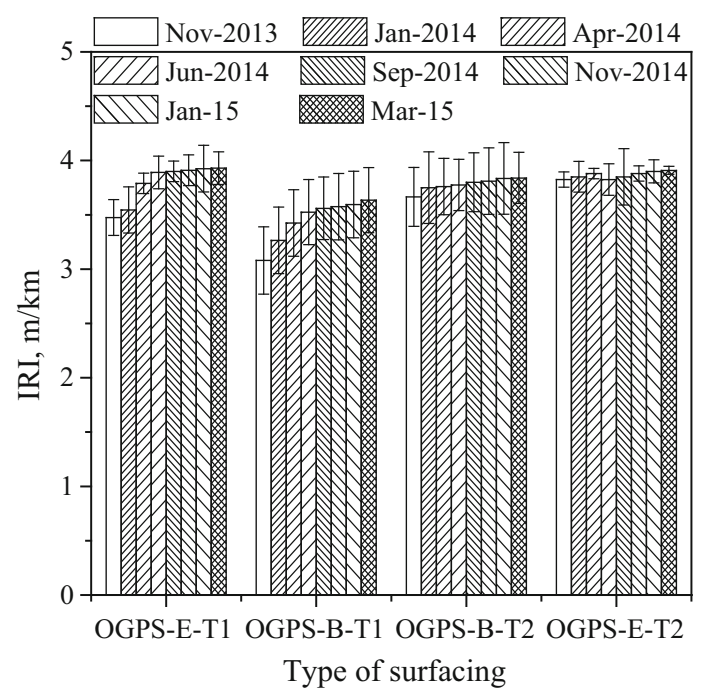

Fig. 4 IRI as a function of surface course type and binder type values for sections constructed using gravel surface course type 1 with bitumen and bitumen emulsion are 3.08 and $3.48 \mathrm{~m} / \mathrm{km}$, respectively. In one and half years (by March 2015), the IRI values over the surface course type $1 \mathrm{sec}-$ tions progressed to 3.64 and $3.93 \mathrm{~m} / \mathrm{km}$, resulting in accumulation of 0.56 and $0.45 \mathrm{~m} / \mathrm{km}$, respectively for bitumen and bitumen emulsion. Similarly, the initial IRI values for sections constructed using gravel surface course type 2 with bitumen and bitumen emulsion are 3.67 and $3.83 \mathrm{~m} / \mathrm{km}$, respectively. In one and half years, the IRI values over the surface course type 2 sections progressed to 3.84 and $3.91 \mathrm{~m} / \mathrm{km}$, resulting in accumulation of 0.17 and $0.08 \mathrm{~m} / \mathrm{km}$, respectively for bitumen and bitumen emulsion. The initial IRI values over gravel surface course type 1 are lower than the gravel surface course 2 . The final IRI values over gravel surface course type 1 are again lower than the gravel surface course type 2 . However, the difference between IRI values between the two surface course types for a given binder type gradually decreased with time. The possible reason might be due to difference in gravel types and aggregates proportion used in both the gravel surface course types. It is important to note here that the IRI values reported in Figs. 2, 3 and 4 are comparable to the values observed by other researchers [8] on similar kind of roads.

\section{Texture Depth}

To assess the texture depth of the road, sand patch test was done along the road section. It is more reasonable to hypothesize that, based on the texture depth, reasonable estimate can be made on possible resistance to bleeding and aggregate retention. Greater the average texture depth, greater is the quantity of material lost in the surface voids. With the onset of bleeding, texture depth gradually decreases as the surface voids are filled with bitumen. Further, higher the texture depth, greater would be the voids over the pavement surface and aggregates are likely to be ravelled. In other words, aggregate retention would decrease with increase in texture depth. The data were collected at regular intervals i.e., in November 2013, January 2014, April 2014, June 2014, September 2014, November 2014, January 2015 and March 2015. Test was done along the road by taking three readings in each section and average values are used to generate plots. The maximum and minimum texture depth values are shown using the range bars. Densification resulting due movement of commercial vehicles would decrease voids between aggregates leading to decrease in texture depth.

The influence of binder type (bitumen, bitumen emulsion), surface course type (surface course type 1, surface course type 2 ), and primer rate (priming 1 , priming 2 ) on texture depth are mutually compared in Figs. 5, 6, 7 and 8. 


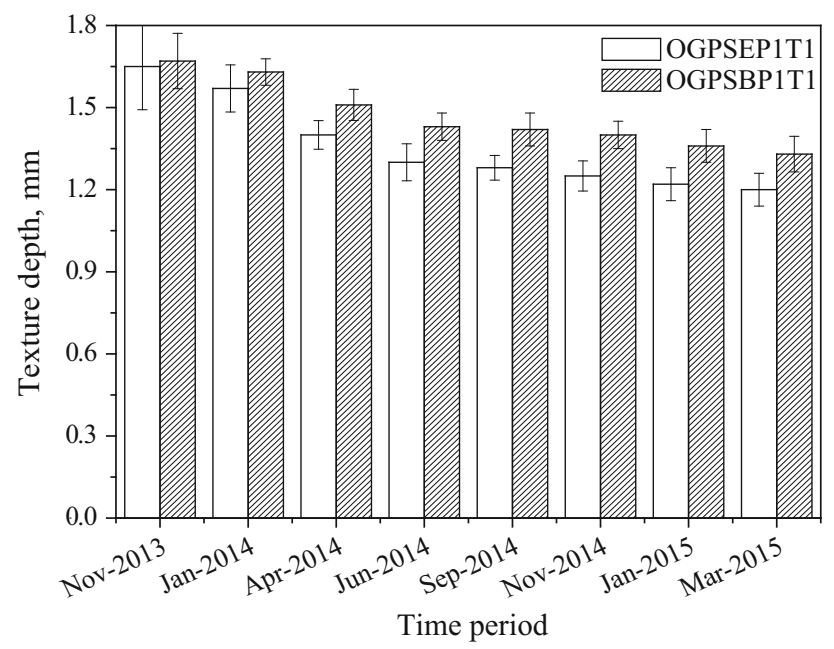

Fig. 5 Texture depth as a function of time for OGPS laid over gravel surface course type 1 with primer rate $9 \mathrm{~kg} / 10 \mathrm{~m}^{2}$

In Fig. 5, emulsion based OGPS (OGPSEP1T1) is compared with bitumen based OGPS (OGPSBP1T1) where surface course type 1 and primer 1 are used. In Fig. 6, emulsion based OGPS (OGPSEP1T2) is compared with bitumen based OGPS (OGPSBP1T2) where surface course type 2 and primer 1 are used. In Fig. 8, emulsion based OGPS (OGPSEP2T1) is compared with bitumen based OGPS (OGPSBP2T1) where surface course type 1 and primer 2 are used. In Fig. 9, emulsion based OGPS (OGPSEP2T2) is compared with bitumen based OGPS (OGPSBP2T2) where surface course type 2 and primer 2 are used.

It can be observed from Figs. 5, 6, 7 and 8 that the texture depth decreased with time for all the variables considered in this study. The traffic might have reduced the surface voids thereby decreasing the texture depth. It can also be observed from Figs. 5, 6, 7 and 8 that the texture depth is higher when bitumen is used as the binder when compared to the case when bitumen emulsion is used as the binder. This difference might be due to variation in air voids of the OGPS layer construction with bitumen and bitumen emulsion.

The difference in texture depth values between sections with bitumen and bitumen emulsion constructed over gravel surface course type 1 is higher than gravel surface course type 2 for both the primer rates. Similar to the IRI values, the possible reason for the variation in texture depths with gravel surface course type might be due to difference in gravel types and aggregates proportion used in both the gravel surface course types. The primer rate has negligible effect on the texture depth as the role of primer is to plug the air voids present over the gravel surface course and to bond the OGPS and the under-lying gravel surface course.

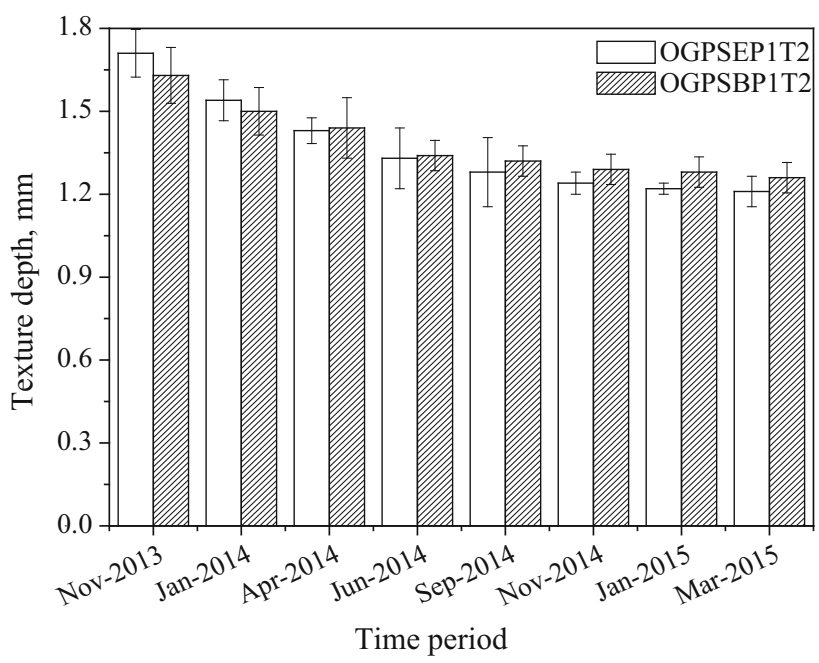

Fig. 6 Texture depth as a function of time period for OGPS laid over gravel surface course type 2 with primer rate $9 \mathrm{~kg} / 10 \mathrm{~m}^{2}$

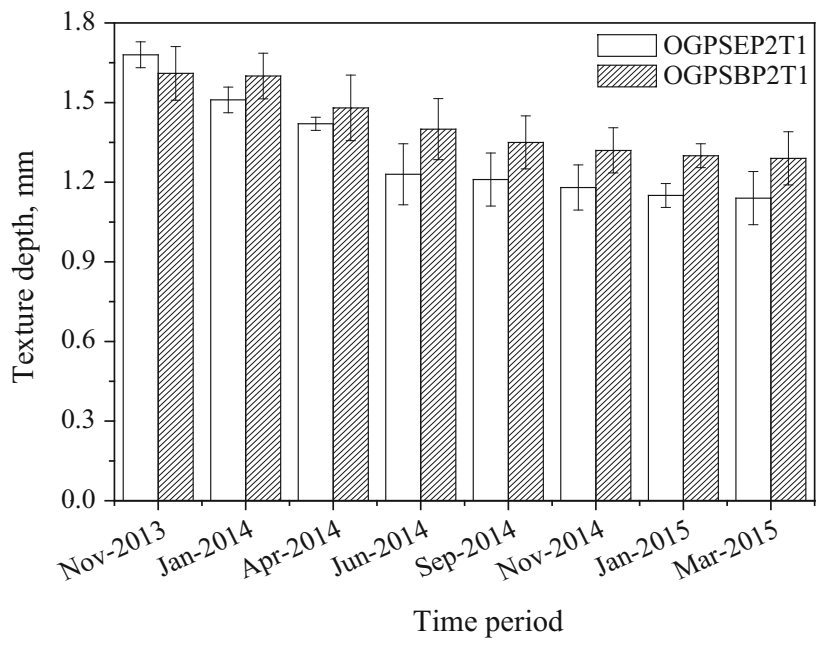

Fig. 7 Texture depth as a function of time for OGPS laid over gravel surface course type 1 with primer rate $12 \mathrm{~kg} / 10 \mathrm{~m}^{2}$

\section{Skid Resistance}

To assess the skid resistance of the road, British pendulum test was performed along the road section. Skid resistance develops between vehicle tyres and the surface of the road and is a function of surface texture. It is the resistance offered by the pavement from skidding of the vehicle. Skid resistance is an important parameter in assessing the functional evaluation of a pavement. It is measured in terms of British pendulum number using British pendulum test. The British pendulum tester is a dynamic pendulum impact-type tester used to measure the energy loss when a rubber slider edge is propelled over a test surface. The greater the friction between the slider and the test surface, the more the swing is retarded, and the larger the BPN 


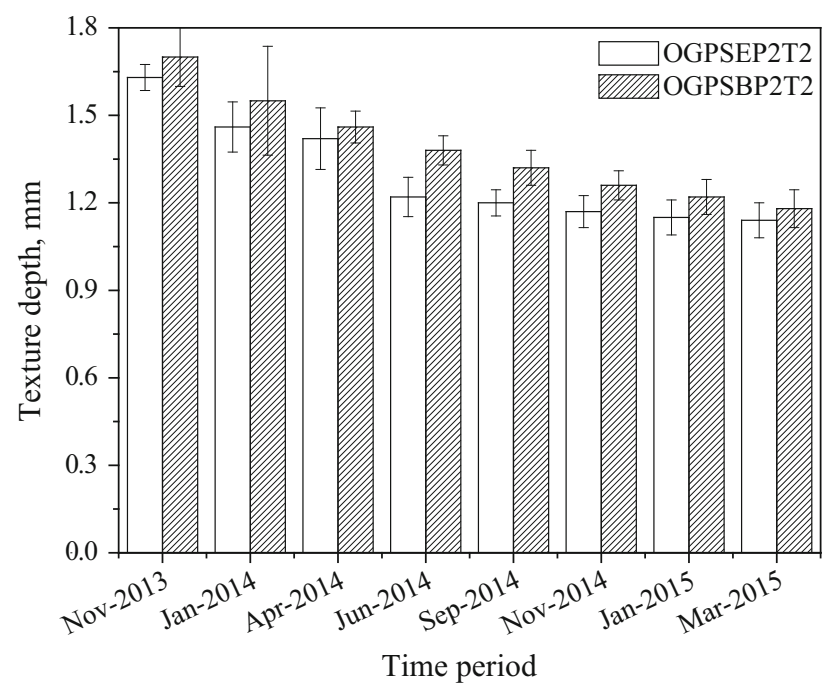

Fig. 8 Texture depth as a function of time for OGPS laid over gravel surface course type 2 with primer rate $12 \mathrm{~kg} / 10 \mathrm{~m}^{2}$

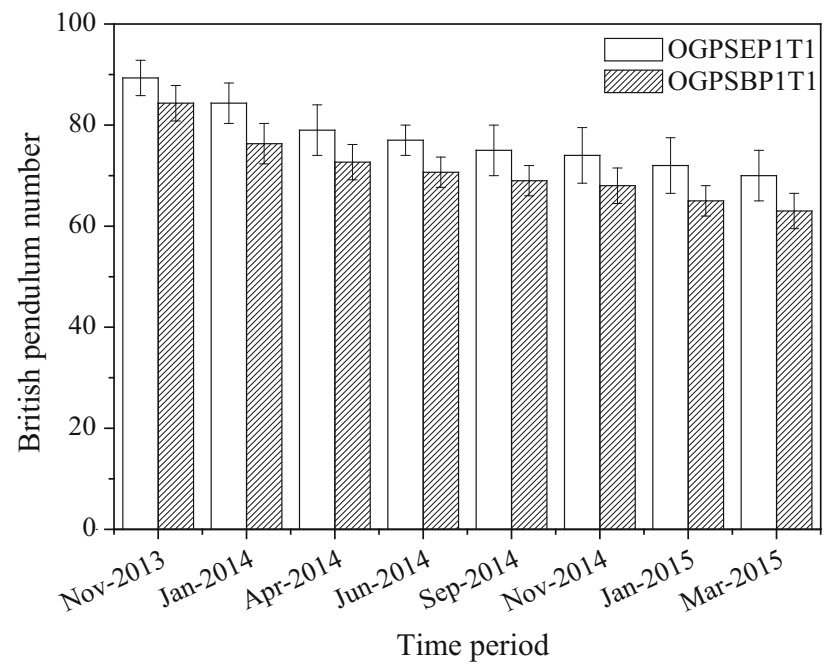

Fig. 9 British pendulum number as a function of time for OGPS laid over gravel surface course type 1 with primer rate $9 \mathrm{~kg} / 10 \mathrm{~m}^{2}$

reading. British pendulum test was performed at different intervals i.e., in November 2013, January 2014, April 2014, June 2014, September 2014, November 2014, January 2015 and March 2015. Test was performed only in dry condition along the road by taking three readings in each section and average values are used to generate plots. The maximum and minimum values are shown using the range bars.

The influence of binder type (bitumen, bitumen emulsion), surface course type (surface course type 1, surface course type 2), and primer rate (priming 1, priming 2) on British pendulum number are mutually compared in Figs. 9, 10, 11 and 12. In Fig. 9, emulsion based OGPS (OGPSEP1T1) is compared with bitumen based OGPS (OGPSBP1T1) where surface course type 1 and primer 1

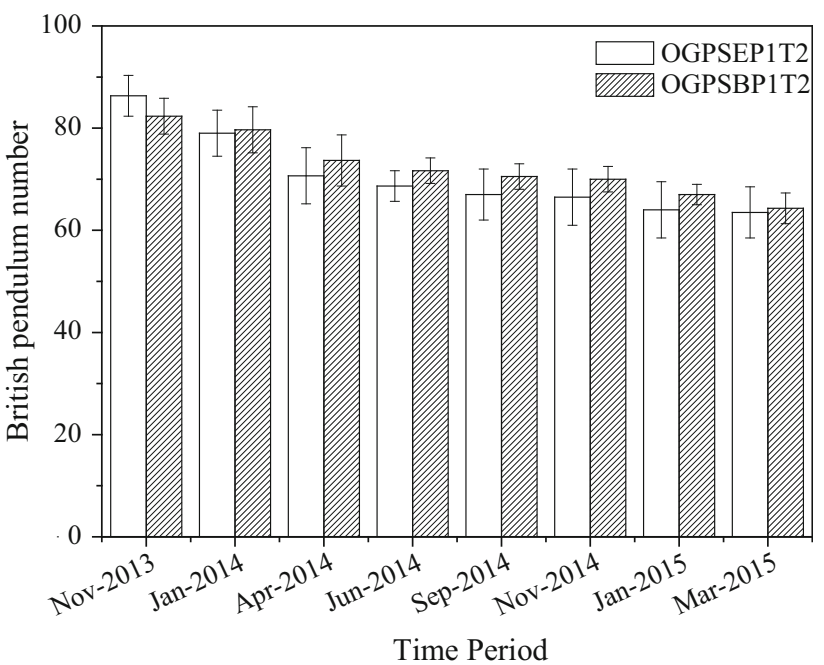

Fig. 10 British pendulum number as a function of time for OGPS laid over gravel surface course type 2 with primer rate $9 \mathrm{~kg} / 10 \mathrm{~m}^{2}$

are used. In Fig. 10, emulsion based OGPS (OGPSEP1T2) is compared with bitumen based OGPS (OGPSBP1T2) where surface course type 2 and primer 1 are used. In Fig. 11, emulsion based OGPS (OGPSEP2T1) is compared with bitumen based OGPS (OGPSBP2T1) where surface course type 1 and primer 2 are used. In Fig. 12, emulsion based OGPS (OGPSEP2T2) is compared with bitumen based OGPS (OGPSBP2T2) where surface course type 2 and primer 2 are used.

It can be observed from Figs. 9, 10, 11 and 12 that the British pendulum number decreased with time for all the variables considered in this study. The aggregate present in the bituminous mix might have undergone polishing effect due to the traffic thereby reducing the British Pendulum number. Since the British pendulum number is related to aggregate characteristics, the effect of bitumen type, gravel surface course type and primer rate has negligible effect on the British pendulum number.

It is worth looking at the possible effect of texture depth on the skid resistance. With passage of vehicles (time) over the pavement surface, the IRI values increased whereas the texture depth and skid resistance values decreased. As the texture depth decreases, more aggregate would come in contact with the vehicular tyres resulting in more polishing of aggregates and resulting decrease in skid resistance. Since texture depth and skid resistance are measured at smaller scales (shorter wavelengths and amplitudes) when compared to the roughness (higher wavelengths and amplitudes), skid resistance cannot be directly related to the IRI values.

\section{Pavement Distresses}

Detailed distress survey was done on the road stretches in September 2014, November 2014, January 2015, and 


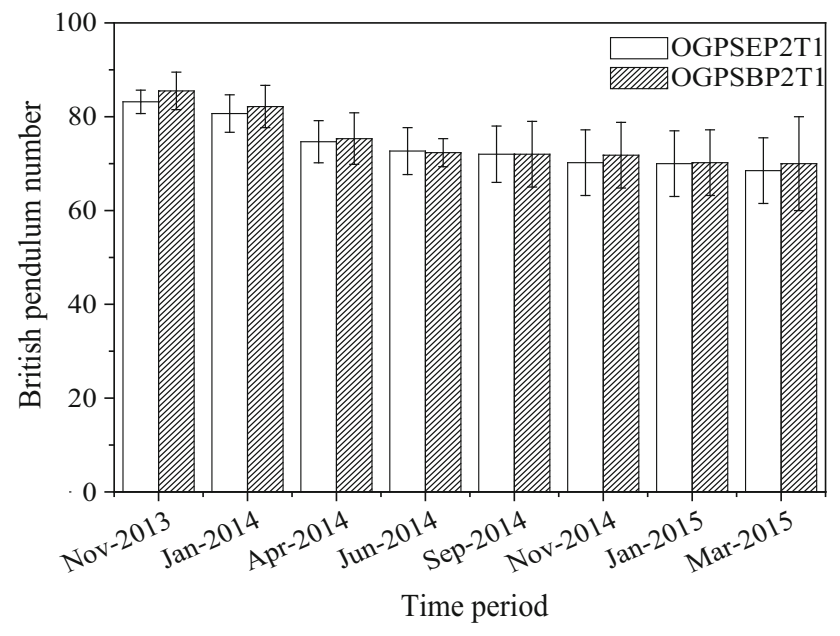

Fig. 11 British pendulum number as a function of time for OGPS laid over gravel surface course type-1 with primer rate $12 \mathrm{~kg} / 10 \mathrm{~m}^{2}$

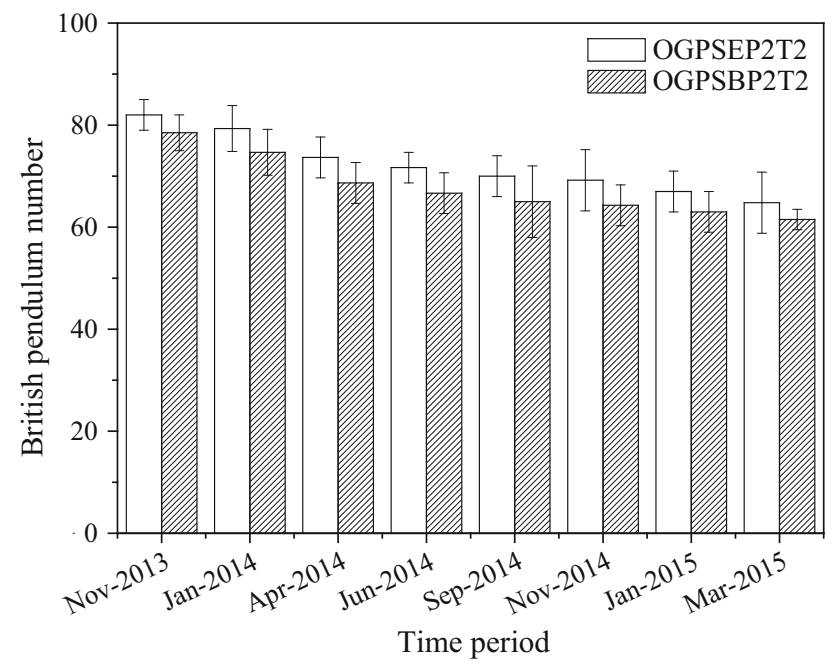

Fig. 12 British pendulum number as a function of time for OGPS laid over gravel surface course type 2 with primer rate $12 \mathrm{~kg} / 10 \mathrm{~m}^{2}$

March 2015. The distresses were found to be more when emulsion based OGPS was used. Edge crack is found to be one major distress. This might be possible due to movement of cage wheeled tractors over the edge of the pavement. Potholes were observed on some of the sections. Agricultural fields are located on either side of the road sections that led to increased movement of cage wheeled tractors over the road sections. Even though there is a restriction on movement of cage wheeled tractors, these vehicles continued to ply over the road stretches even after erecting a sign board as shown in Fig. 13. This led to the generation of potholes on some of the sections of the road. Figure 14 shows the OGPS sections with bitumen and bitumen emulsion immediately after road construction.
The rut depth along the selected pavement sections was measured in conformity to the American Society for Testing and Materials (ASTM) standard test procedure using a straightedge [22]. Rutting was very less and not observed on all the sections since the movement of heavy loaded vehicles on this road is less. Figure 15 shows the representative rut depth on various sections at different times along with the maximum and minimum values marked using the range bars. It can be seen that rutting was observed only in bitumen based open graded premix surfacing with surface course type-1 with primer rate $12 \mathrm{~kg}$ / $10 \mathrm{~m}^{2}$ (OGPSBP2T1), where the rut depth increased rapidly with time. In this section, gravel surface course type 1 , bitumen binder, and primer rate of $12 \mathrm{~kg} / 10 \mathrm{~m}^{2}$ were used. The possible reason might be due to the presence of a small pond adjacent to this section resulting in localized failure.

Figure 16 shows ravelling on different sections. Ravelling was not observed on all the sections and found to be higher on the section where emulsion based OGPS is used. It is important to note that no ravelling was observed on other sections where bitumen emulsion is used. Figure 17 shows the percentage area of potholes for different sections. It is interesting to note that potholes were observed only in the sections where bitumen emulsion is used as the binder. Rutting, ravelling, and pot holes are inter-related. Formation of ruts results in stagnation of rain water over the pavement surface which results in stripping and subsequent dislodgement of aggregates from the pavement surface. Continued dislodgement of aggregates results in the formation of pot holes. Figure 18 shows the edge cracking on different sections. Similar to pot holes, edge cracking was observed to be more on sections where bitumen emulsion is used as the binder. However, less edge cracking was observed on the sections where bitumen is used as the binder, that too with gravel surfacing type 2 . The percentage change in the growth of edge cracking is negligible when compared to other distresses. Movement of cage wheels might be the possible reason for the occurrence of edge cracking.

\section{Conclusions}

Following are the conclusions drawn from this study:

- Roughness increased with time. The roughness values are less in stretches where OGPS with bitumen is used when compared to the stretches of OGPS with bitumen emulsion. The possible reason is ascribed to the stiffness of the bitumen binder. Since bitumen emulsion consists of fine globules of bitumen dispersed in an aqueous phase, the stiffness of parent bitumen used in 
Fig. 13 Sign boards of PMGSY and restriction on tractors with cage wheels
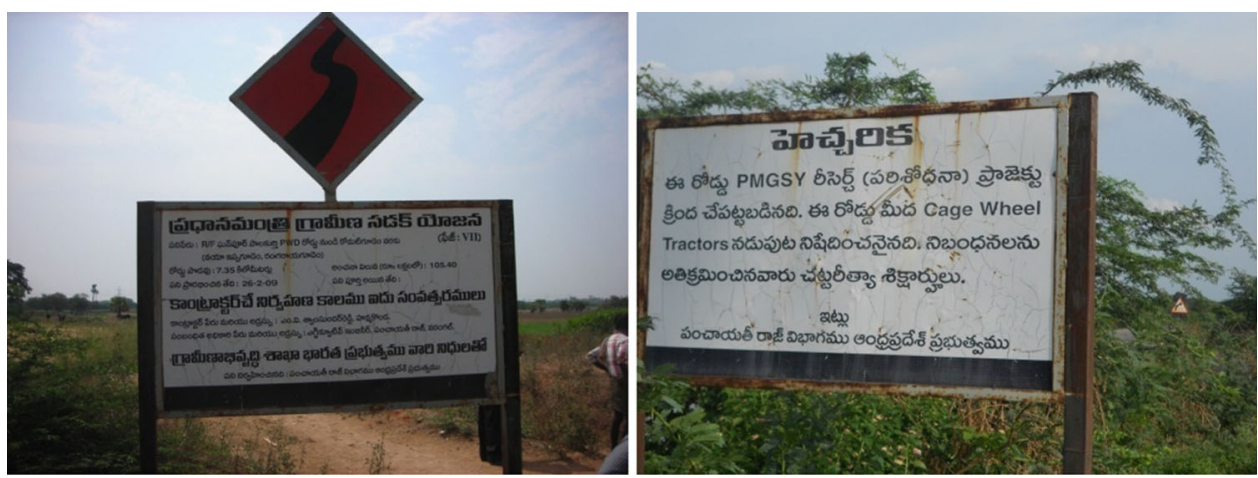

Fig. 14 OGPS sections with bitumen and bitumen emulsions as the binders
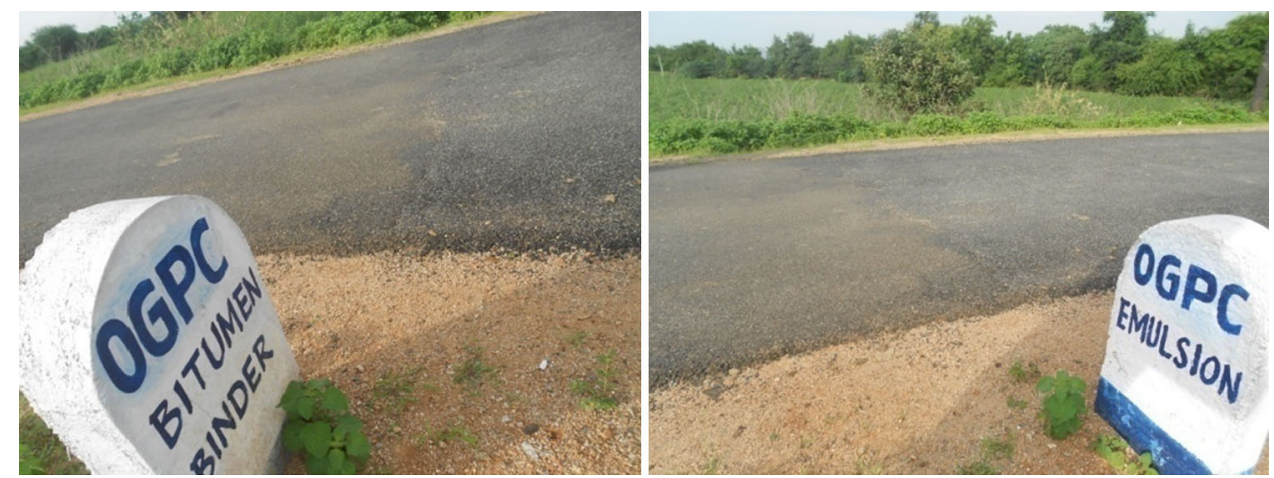

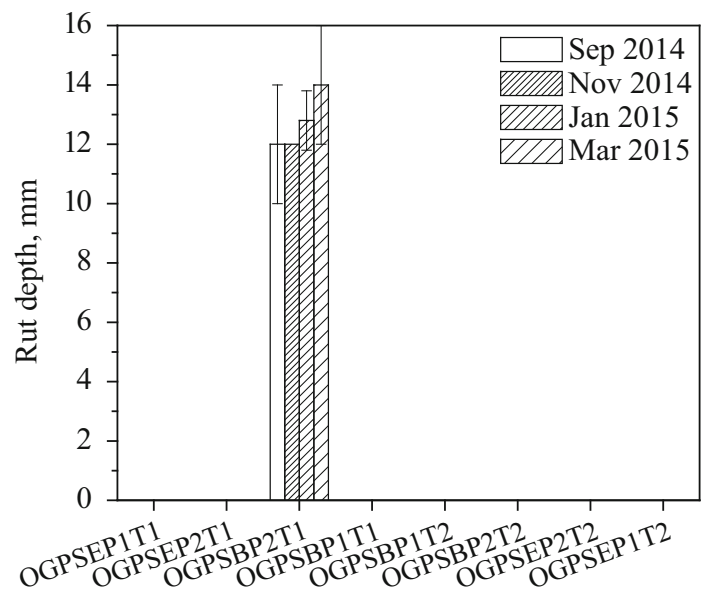

Type of surfacing

Fig. 15 Average rut depths in different sections with respect to time

bitumen emulsion might be lower than stiffness of bitumen used in the stretches of OGPS with bitumen binder. This might have resulted in higher roughness values when bitumen emulsion is used as the binder.

- Texture depth decreased with time. The texture depth is higher when bitumen is used as the binder when compared to bitumen emulsion as the binder.

- British pendulum number decreased with time. British pendulum number depends on the polishing resistance

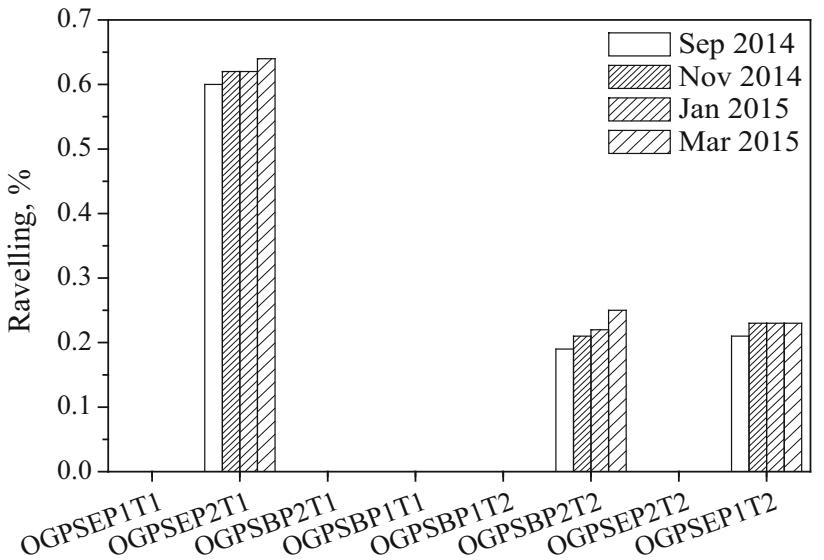

Type of surfacing

Fig. 16 Raveling in different sections with respect to time

of the aggregate used for the construction of the wearing course. The British pendulum number is not affected by the bitumen type, gravel surface course type and primer rate.

- Since the roughness, texture depth, and British pendulum number progressed continuously as a function of time, this warrants for the development of distress progression models considering the above distresses for the pavement test stretches considered in this study. 


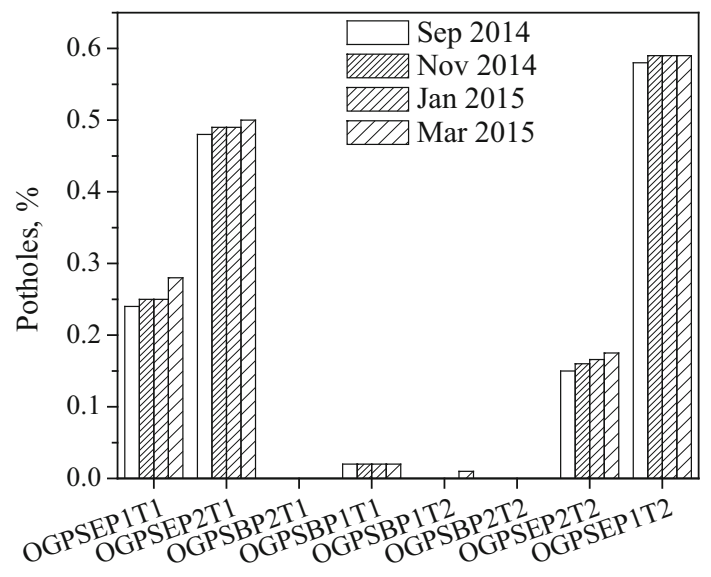

Type of surfacing

Fig. 17 Potholes in different sections with respect to time

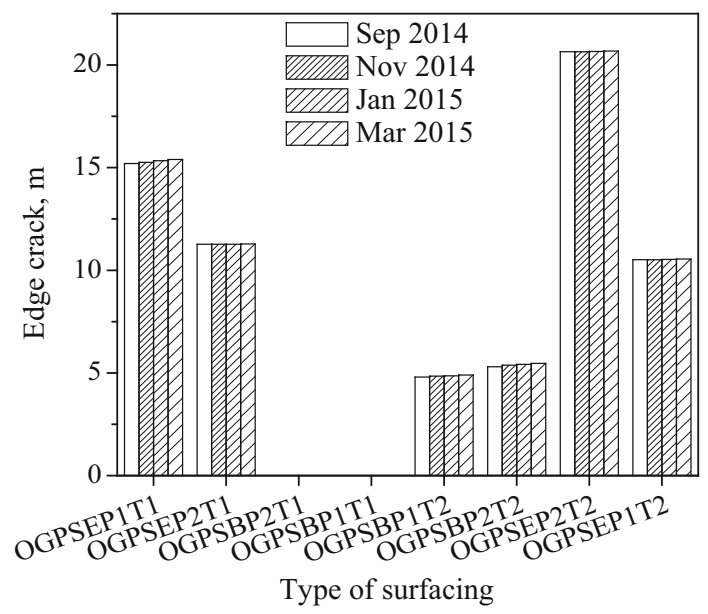

Fig. 18 Edge cracking in different sections with respect to time

- Distresses such as rutting, ravelling, pot holes, and edge cracking are evaluated at regular intervals. It is observed that the distresses are higher when bitumen emulsion is used as the binder. Even though there is movement of tractors fitted with cage wheels on these road stretches, the performance of OGPS sections with bitumen is better than bitumen emulsion. Other variables including gravel surface type and primer rate has negligible effect on the performance of the pavements.

- Based on the analysis of data collected till now, the performance of OGPS section constructed with VG-10 bitumen, for both priming rates ( 9 and $12 \mathrm{~kg}$ per $10 \mathrm{~m}^{2}$ ) and for both the gravel surface course types resulted in better performance when compared to the sections with bitumen emulsion as the binder. However, this observation need to be verified by evaluating the performance of pavements constructed with similar crosssection under varied traffic and climatic conditions.
Acknowledgments The authors acknowledge the National Rural Roads Development Agency, Ministry of Rural Development, Government of India for sanctioning this research project and Panchayat Raj Engineering Department, Government of Telangana for executing the road construction. The authors would like to acknowledge the services of Panchayat Raj Engineers involved in the construction of the road stretches. The authors acknowledge the opportunity to present the research work that forms the basis of this article at the 3rd Conference of the Transportation Research Group of India held at Kolkata (India) from 17 to 20 December, 2015.

\section{References}

1. PMGSY (2005) Operations manual. Pradhan Mantri Gram Sadak Yojana, National Rural Roads Development Agency, Ministry of Rural Development, Government of India, New Delhi, India. http://pmgsy.nic.in/op1.htm. Accessed 17 April 2016

2. PIB (2015) Government brings forward the target date for full completion of rural road connectivity under PMGSY by 3 years, Press Information Bureau, Government of India, New Delhi, India. http://pib.nic.in/newsite/PrintRelease. aspx?relid=131846. Accessed 17 April 2016

3. Levik K (2001) How to sell the message "Road maintenance is necessary" to decision makers. First Road Transportation Technology Transfer Conference in Africa, Arusha, Tanzania

4. Overby C, Pinard MI (2013) Otta seal surfacing: practical and economic alternative to traditional bituminous surface treatment. Transp Res Record J Transp Res Board 2349:136-144

5. Croney D (1972) Failure criteria for flexible pavements. In: Proceedings of Third International Conference on Structural Design of the Asphalt Pavements, University of Michigan, Ann Arbor, Michigan, pp 608-612

6. Pidwerbesky BD, Steven BD, Arnold G (1997) Subgrade strain criterion for limiting rutting in asphalt pavements. In: Proceedings of Eighth International Conference on Asphalt Pavements, Seattle, Washington, pp 1529-1544

7. Sahoo UC, Reddy KS (2011) Performance criterion for thinsurface low-volume roads. Transp Res Record J Transp Res Board 2203:178-185

8. Sahoo U, Ahmed S, Reddy KS (2014) Long term performance evaluation of rural roads in India. Design, analysis, and asphalt material characterization for roads and airfield pavements, GSP 246, pp 91-98

9. Yacoob H, Hainin MS, Woodward D, Woodside A (2008) Changes of surface dressing texture as related to time and chipping size. Malays J Civil Eng 20(1):1-11

10. Gransberg D (2007) Using a New Zealand performance specification to evaluate US chip seal performance. J Transp Eng 133(12):688-695

11. Labi S, Sinha KC (2004) Effectiveness of highway pavement seal coating treatments. J Transp Eng 130(1):14-23

12. Gransberg D, Zaman M (2005) Analysis of emulsion and hot asphalt cement chip seal performance. J Transp Eng 131(3):229-238

13. Howard IL (2011) Preservation of low-volume flexible pavement structural capacity by use of seal treatments. Transp Res Record J Transp Res Board 2204:45-53

14. Oloo S, Lindsay R, Mothilal S (2001) Otta seals and Gravseals as low-cost surfacing alternatives for low-volume roads: experiences in South Africa. Transp Res Record J Transp Res Board 1819:338-342

15. Grazulyte J, Zilioniene D, Tuminiene F (2014) Otta seal-the new way to solve problems of maintenance of gravel roads in Lithuania. In: The 9th International Conference "Environmental Engineering", Vilnius, Lithuania 
16. Johnson G (2003) Minnesota's experience with thin bituminous treatments for low-volume roads. Transp Res Record J Transp Res Board 1819:333-337

17. Cook J, Petts R, O’Neill P (2008) Appropriate surface sealing for sustainable low volume rural roads in Vietnam. In: First Sprayed Sealing Conference-Cost Effective High Performance Surfacings, Adelaide, Australia

18. Cross SA, Voth MD, Shrestha PP (2005) Guidelines for prime coat usage on low-volume roads. Transp Res Record J Transp Res Board 1913:117-125

19. IRC (2008) Manual for design, construction and maintenance of gravel roads, IRC Special Publication 77, Indian Roads Congress, New Delhi, India
20. MoRD (2014) Specifications for Rural Roads, Ministry of Rural Development, Indian Roads Congress, New Delhi, India

21. Cundill MA (1996) The MERLIN road roughness machine: user guide, Transportation Research Laboratory Report 229, Berkshire, UK

22. ASTM (2010) Standard test method for measuring rut-depth of pavement surfaces using a straight edge, ASTM Standard E1703, American Society for Testing and Materials International, West Conshohocken, Pennsylvania, USA 